\title{
The Effect of Implant Neck Design on the Crestal Bone Levels that Support the Tissue Around the Implant - Restoration
}

\author{
Nazih Issa, Naser Bahrli, Modar Ahmad* \\ Department of Prosthodontic, Faculty of Dentistry, Tishreen University, Latakia, Syria
}

Email address:

Modarnet00@hotmail.com (M. Ahmad),nazihissa8@gmail.com (N. Issa), naser.bahrli059@outlook.com (N. Bahrle)

To cite this article:

Nazih Issa, Naser Bahrli, Modar Ahmad. The Effect of Implant Neck Design on the Crestal Bone Levels that Support the Tissue Around the Implant-Restoration. American Journal of Biomedical and Life Sciences. Vol. 3, No. 4, 2015, pp. 75-83. doi: 10.11648/j.ajbls.20150304.12

\begin{abstract}
This research aims to evaluate the impact of the shape of the implant neck on the level of crestal bone surrounding it. Dental implant surgeries were performed, and prosthesis were placed over (28) implants in six jaws for five patients (5 upper jaws and 1 lower jaw). These dental implant surgeries were performed on the jaws such that one of the sides received 2 or 3 implants from the BICON system with beveled neck, while the opposite side received the same number of implants from the ONB system from IDI with non-beveled neck. The implant-restorations were then performed following complete osseointegration. The patients were observed via periodic panoramic radiographs starting from the day the prosthesis were placed, then 3 months after the restoration, 6 months after the restoration and 18 months after the restoration. The distance between the implant neck and the point of contact of the crestal bone with the implant neck (mesial and distal) was measured for each implant using periodic panoramic radiographs taken for every patient. The results revealed the occurrence of periimplant crestal bone loss, known as the saucerization phenomenon. Independent samples T-test was conducted to compare the mean bone loss with both types of implants mentioned above. The results of the study did not show any statistically significant differences in the early stages of the restoration/prosthesis. Yet, after 6 months and up to 18 months post restoration, statistically significant differences emerged verifying that the peri-implant bone loss occurring in implants with a beveled neck was less than that occurring around implants with a non-beveled neck, confirming the incidence of an initial bone loss following the restoration in all cases. This research revealed that the design of the implant yields better esthetic results in the presence of a bevel in the implant neck, taking into consideration the occurrence of a definite bone loss.
\end{abstract}

Keywords: Implant Neck, Crestal Bone, Implant Neck Design

\section{Introduction}

Teeth loss, particularly in the anterior zone of the jaws creates both a major esthetic problem as well as a major functional problem. This in turn requires a permanent prosthesis, capable of providing the best solution for both the esthetic and functional problems [1]. Given that the esthetic aspect of the teeth is largely determined by the shape of the crown and the surrounding tissue, especially at the gingival margins it is hence very important that these tissues are symmetrical and have specific characteristics.

The gingival papilla in the anterior esthetic zone of the jaws is pyramidal-conical in shape and extends to half of the corresponding length of the dental crown. It is supported by the crestal bone that is connected to its base section[2].

The peri-implant crestal bone loss leads to a loss in the gingival tissue above this bone[3,4,5]. This in turn negatively affects the esthetic aspect of this zone [6], as well as causing the formation of an undesirable pocket that has adverse effects on the health of the peri-implant tissue [7].

This peri-implant bone loss that occurs after functional loading is known as saucerization $[8,9,10]$.

The design of the implant neck affects the amount of periimplant bone loss $[11,12]$ thus several firms have made a beveled on the implant neck, claiming that it preserves the peri-implant cerstal bone [13] because it provides a place for the bone. This has stimulated research in an aim to uncover the effect of the differences in the design of the implant neck on the adjacent bone levels for the implant-restoration. This research is considered among the first scientific researches that studied the difference between a beveled neck and a nonbeveled neck for dental implants. 


\subsection{The Scientific Problem and Research Motivations}

The problem of the research was the incidence of periimplant bone loss following the functional loading. This bone loss has a apical direction, known as the saucerization phenomenon $[8,9,10]$ "Fig. 1 ".

\subsection{Research Significance and Goals}

This research aims to evaluate the impact of the shape of the implant neck on the level of the crestal bone surrounding it.

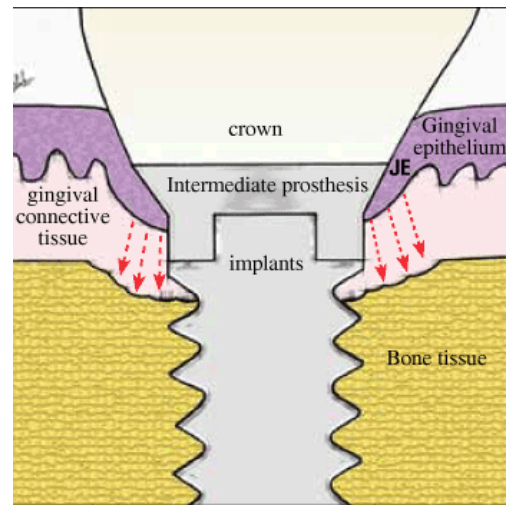

Figure 1. Saucerization Phenomenon.

\section{Materials and Methods}

\subsection{Research Sample}

The study sample was comprised of 28 implants, half of which were implants with beveled neck and the other half were implants with non-beveled neck. The implants were inserted in the jaws of five patients who had multiple tooth loss in the anterior zone on both sides of the jaw mid-line. Each of the patients had sought the appropriate treatment to receive (4-6) adjacent dental implants in the anterior zone in one or both jaws to replace the loss.

\subsection{Materials}

- Fully-equipped dentist chair.

- Dental implant motor, "Fig. 2".

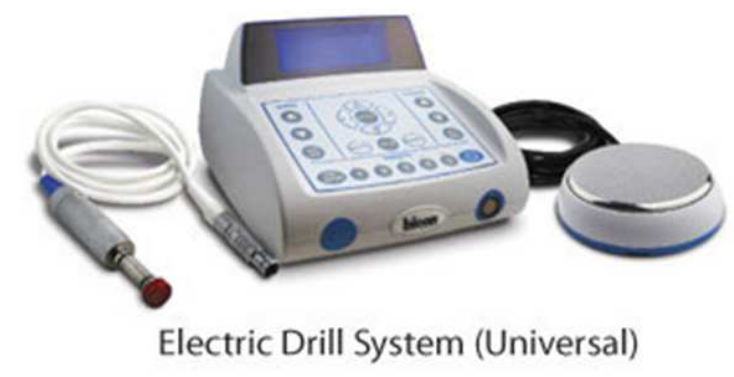

Figure 2. Dental implant motor.

- BICON implants tool kit, "Fig. 3".

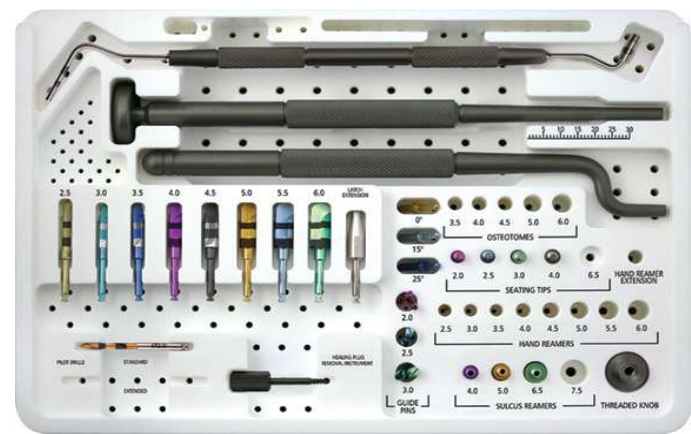

Figure 3. BICON implant tool kit.

- IDI implants tool kit, "Fig. 4".

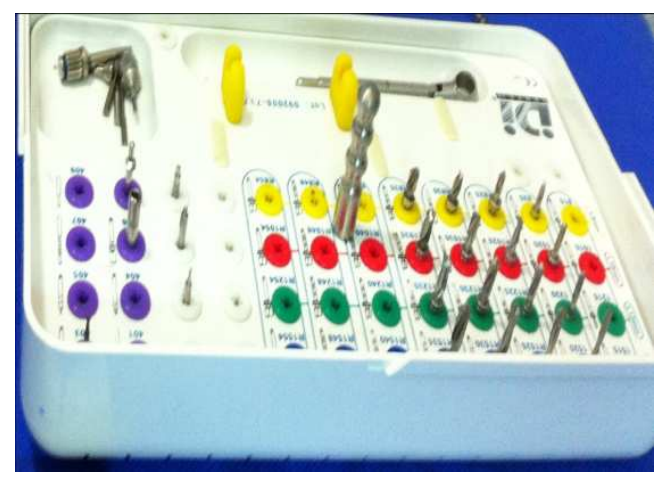

Figure 4. IDI implant tool kit.

- Diagnostic tools (mirror, forceps, probe).

- Minor surgical tools (blade, scalpel holder, periosteum separator, section seperator, surgical needles and threads).

- Panoramic radiographs.

- A sample of patients in need of and have sought treatment, (28) implants- half of which were of the BICON system with a beveled neck, "Fig. 5". and half of which were of the IDI system( ONB) implants with a non-beveled neck (this neck is similar to the majority of the implant necks in other implant systems), "Fig. 6".

\section{THE BICON SYSTEM}
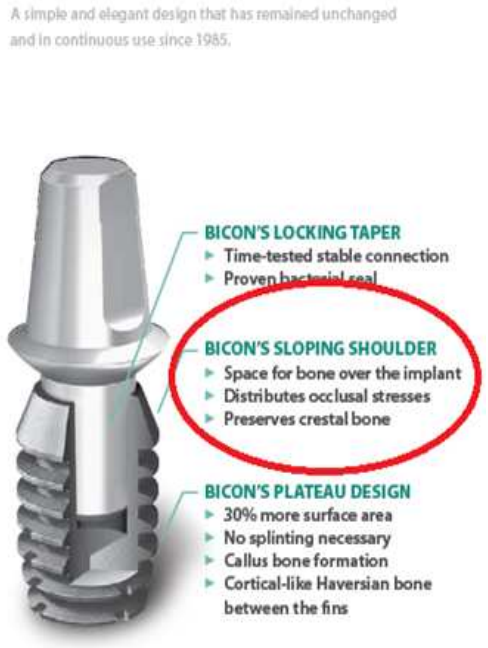

Figure 5. BICON Implant. 


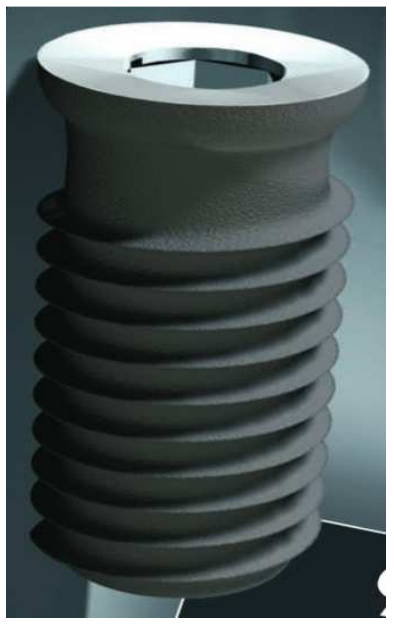

Figure 6. ONB Implant from IDI system.

\subsection{Research Methodology}

\subsubsection{The Dental Implant Surgery}

In a dental implant operation room equipped with the aforementioned:

-An IDI implant site was prepared at a motor speed of 500600 rotations/minute while irrigating the first drill (pilot) and at a speed of 350 rotations/minute while irrigating the remaining drills.

-BICON implant site was prepared in the same manner for the first drill, and then at a lower motor speed of 50 rotations/minute without cooling so as to gather the largest possible amount of bone from the drilling site.

-An appropriate site was drilled for every implant in accordance with its diameter, length, and depth below the bone so that the surfaces of all the implant necks were placed beneath the bone level.

-The IDI implants were inserted by twisting them into the desired depth within their cavities, whereas the BICON implants were inserted into their respective sites gently. The BICON system drills provide an amount of bone to be used as a bone-bait. This bait was used above the submerged, beveled neck implants (as indicated by BICON company).

-Later, the plastic holder was cut away from the BICON implants and the covering screw was placed above the IDI implants. The section was closed by performing a tight, single suture to ensure the stability of the bone- bait above the implant necks for a period of 10 days, after which the suturing was undone.

\subsubsection{Prosthetic Phase}

The implants were exposed by making a longitudinal section at the tip of the crestal margin to verify the osseointegration by tapping the implant and listening to a ringing sound.

After confirming the health of the implants, the accompanying healing abutments were placed to shape the gingivae. An abutment of a $5 \mathrm{~mm}$ diameter was used as a substitute for a heal abutment for the BICON implants, in accordance with the instructions of the manufacturing company, "Fig. 7,a".In the same time a traditional healing abutment for ONB implants were used "Fig. 7,b", The section was closed using single sutures between the heal abutment.

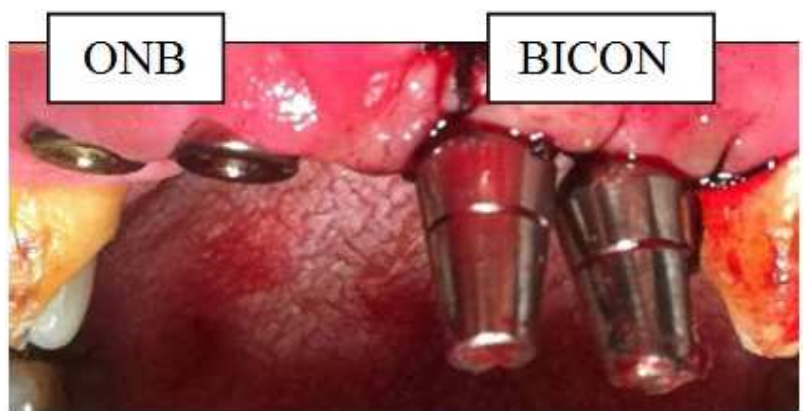

Figure 7a. ONB Healing abutments \& Bicon 5 mm abutments

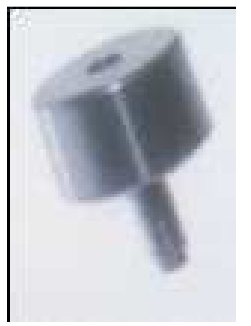

Figure 7b. ONB healing abutment.

\subsubsection{The Impression}

The healing abutments were removed after one week and an impression was taken for the implants of both systems simultaneously, according to the following:

\subsubsection{BICON Implants}

The impression was made following these steps, outlined in "Fig. 8":

1. The impression-transfer post was fastened in the implant using fingertip pressure.

2. The post was covered with the special impression plastic cover, and the impression was taken.

3. The post was removed and connected to an implant analog.

4. The unit [post-implant analog] was inserted within the plastic cover present in the implant.

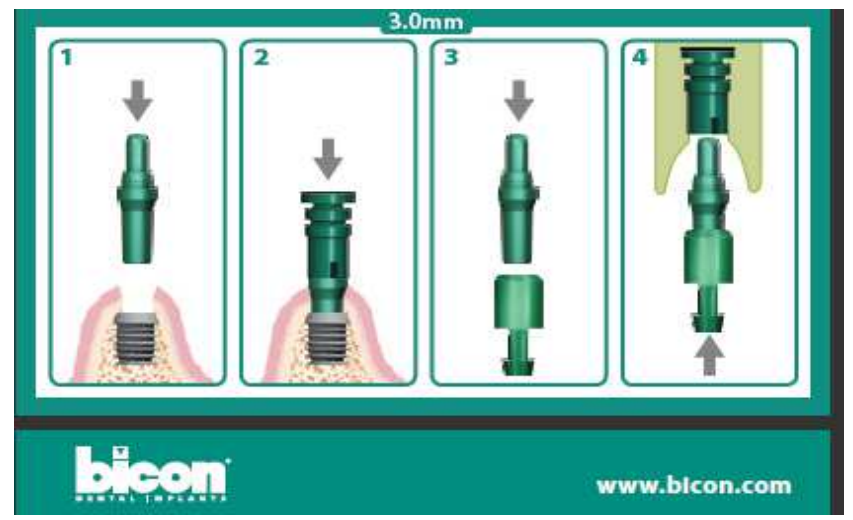

Figure 8. Explanatory diagram for the method of taking an impression in the BICON system. 


\subsubsection{IDI Implants}

1. The impression transfer was fastened in the implant by tightening the screw, "Fig. 9" and impression was made.

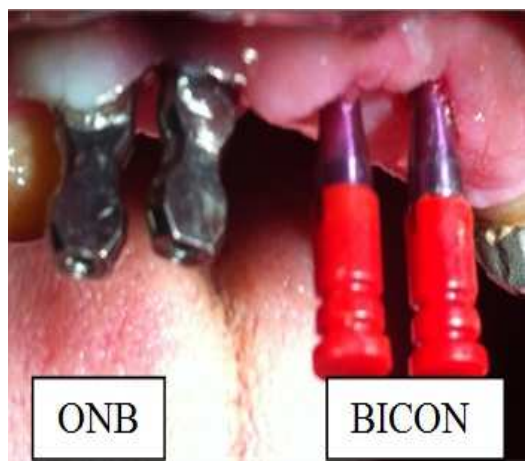

Figure 9. Impression Transfers.

2. The impression transfer was unscrewed and an implant analog was fixed on it. The transfer was then returned to its place in the impression.

The impression was casted in gypsum after applying gingival acrylic at the neck of every implant analog for both systems, so as to mimic the peri-implant tissue in the mouth.

\subsubsection{The Restoration/Prosthesis}

The BICON system is designed based on the concept of (platform switching) which is not present in the IDI system used in this study, thus to unify the conditions of the study for all patients examined and to realize this concept, we used abutments with diameters that are smaller than those of the implant necks in the following manner:

Implant abutments with a diameter of $3.2 \mathrm{~mm}$ were used above implants with a diameter of $3.7 \mathrm{~mm}$. As for the $3.2 \mathrm{~mm}$ implants, we beveled the shoulder present on the perimeter of the abutment in a homogenous manner so that the diameter of the abutment becomes smaller than the diameter of the implant neck.

The abutments were placed in their places in the gypsum cast (tapping the BICON abutments and tightening the screws in the IDI abutments). They were prepared appropriately to receive the crowns "Fig. 10,a".

After ensuring the safety of the preparation the laboratory commenced manufacturing the ceramic-metal crowns.

The bite was recorded with an appropriate vertical dimension and in line with the patient's appropriate smile line.

After the laboratory work was finished the abutments were fastened inside the mouth and the final restoration was cemented above it, "Fig. 10,b".

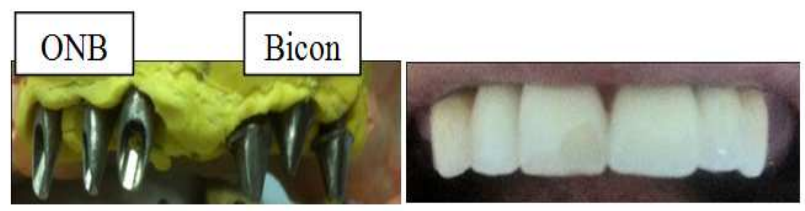

Figure 10. a.(Left) Prepared abutments, b.(right) The restoration/prosthesis.

\subsubsection{Observation}

A panoramic radiograph of the patient was taken immediately after the restoration was placed. After that, periodic panoramic radiographs were taken every 3 months. In every radiograph, the level of bone loss from the implant neck was measured using Digora software, which is used specifically to measure radiographs.

Digora software specializes in reading dental radiographs and it was used in this study to record the measurements. The radiograph was entered using the software and the standardization of the radiograph was selected. The dimension standardization was done in accordance with the recognized, predetermined dimensions of the implant. The dimensions between every implant neck of both systems and the connected bone level was measured as can be seen in "Fig. 11".

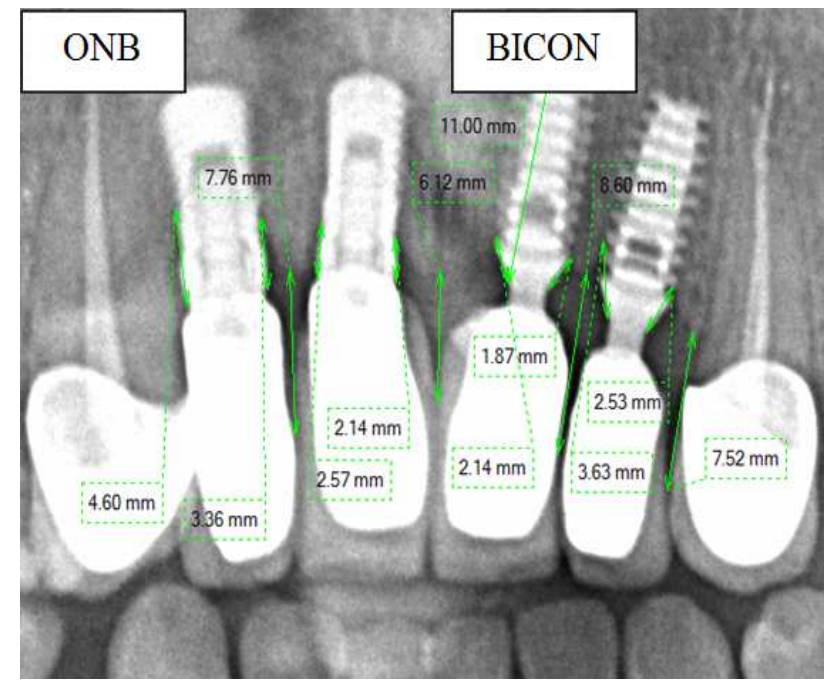

Figure 11. Measurement of dimensions on the radiograph.

\section{Results}

Dental implant surgeries and restorations were performed on (28) implants in 6 jaws for 5 patients ( 5 upper jaws and 1 lower jaw). The dental implant surgeries were performed on the jaws such that one of the sides received 2 or 3 implants from the BICON system with beveled neck, while the opposite side received the same number of implants from the ONB system from IDI with non-beveled neck. The implantrestorations were then performed following complete osseointegration. The patients were observed via periodic panoramic radiographs starting from the day the restoration were placed, then 3 months after the restoration, 6 months after the restoration and 18 months after the restoration.

The distance between the implant neck and the point of contact of the crestal bone with the implant neck (mesial and distal) was measured for each implant by means of periodic panoramic radiographs taken for every patient as outlined in "Table. 1", below. 
Table 1. Measurements of bone-level taken around the neck of every implant.

\begin{tabular}{|c|c|c|c|c|c|c|c|c|c|c|c|c|}
\hline $\begin{array}{l}18 \text { months } \\
\text { after the } \\
\text { restoration }\end{array}$ & $\begin{array}{l}6 \text { months } \\
\text { after the } \\
\text { restoration }\end{array}$ & $\begin{array}{l}3 \text { months } \\
\text { after the } \\
\text { restoration }\end{array}$ & $\begin{array}{l}\text { The Day of } \\
\text { the } \\
\text { restoration }\end{array}$ & Side & $\begin{array}{l}\text { Tooth } \\
\text { Nr. }\end{array}$ & Patient & $\begin{array}{l}\text { Tooth } \\
\text { Nr. }\end{array}$ & Side & $\begin{array}{l}\text { The Day of } \\
\text { the } \\
\text { restoration }\end{array}$ & $\begin{array}{l}3 \text { months } \\
\text { after the } \\
\text { restoration }\end{array}$ & $\begin{array}{l}6 \text { months } \\
\text { after the } \\
\text { restoration }\end{array}$ & $\begin{array}{l}18 \text { months } \\
\text { after the } \\
\text { restoration }\end{array}$ \\
\hline \multicolumn{7}{|c|}{ Non-Beveled Implant Neck } & \multicolumn{6}{|c|}{ Beveled Implant Neck } \\
\hline 1 & 0.6 & 0.8 & 0.4 & Mesial & 11 & 1 & 21 & Mesial & 1.6 & 1.8 & 1.8 & 1.9 \\
\hline 0.7 & 0.7 & 0.8 & 0.2 & Distal & & & & Distal & 1.6 & 1.6 & 2.3 & 3.1 \\
\hline 1 & 0.4 & 0.2 & 0.2 & Mesial & 12 & & 22 & Mesial & 1.2 & 1.1 & 0.8 & 1.3 \\
\hline 4 & 4.3 & 3.3 & 2.7 & Distal & & & & Distal & 0.1 & 1.6 & 1.1 & 1.2 \\
\hline - & - & - & 10 & Mesial & 13 & & 23 & Mesial & 1.7 & 1.6 & 1.7 & 1.4 \\
\hline- & - & - & 0.4 & Distal & & & & Distal & 1.2 & 1.1 & 1.1 & 1.4 \\
\hline 1.8 & 1.5 & 1.3 & 0.9 & Mesial & 41 & & 31 & Mesial & 1.6 & 1.9 & 2 & 1.9 \\
\hline 1.9 & 1 & 0.6 & 0.5 & Distal & & & & Distal & 1.4 & 1.4 & 1.6 & 1.4 \\
\hline- & - & - & - & Mesial & 42 & & 32 & Mesial & 1.4 & 1.5 & 1.5 & 1.5 \\
\hline- & - & - & - & Distal & & & & Distal & 1.1 & 0.6 & 1 & 1.1 \\
\hline 3.8 & 4.1 & 4.1 & 1 & Mesial & 11 & 2 & 21 & Mesial & 1.3 & 2 & 2 & 2.7 \\
\hline 1.5 & 1.5 & 0.3 & 0.2 & Distal & & & & Distal & 1.5 & 1.7 & 1.8 & 1.7 \\
\hline 4.2 & 4.5 & 2.9 & 2.2 & Mesial & 12 & & 22 & Mesial & 1.5 & 1.5 & 1.7 & 2.1 \\
\hline 4.5 & 4 & 3.1 & 1.2 & Distal & & & & Distal & 1.6 & 1.6 & 2.2 & 2.4 \\
\hline 3.9 & 4.3 & 3.8 & 3.5 & Mesial & 13 & & 23 & Mesial & 2.6 & 2.7 & 2.6 & 2.7 \\
\hline 3.2 & 4.5 & 4.4 & 4.6 & Distal & & & & Distal & 3.2 & 3.3 & 3.3 & 2.9 \\
\hline- & - & - & - & Mesial & 21 & 3 & 11 & Mesial & 1.5 & 1.2 & 1.4 & 1.8 \\
\hline - & - & - & - & Distal & & & & Distal & 1.4 & 1.3 & 2 & 2.2 \\
\hline 3.7 & 3 & 2.6 & 2.8 & Mesial & 22 & & 12 & Mesial & 1.9 & 2.5 & 2.5 & 2.7 \\
\hline 2.4 & 2.3 & 1.9 & 1.9 & Distal & & & & Distal & 1.6 & 2.2 & 2.4 & 2.4 \\
\hline 3.5 & 2.7 & 2.4 & 1.5 & Mesial & 11 & 4 & 21 & Mesial & 1.6 & 1.9 & 2 & 2.2 \\
\hline 3.7 & 3.4 & 3.3 & 1.8 & Distal & & & & Distal & 1.4 & 1.7 & 1.8 & 2.6 \\
\hline 3.6 & 3.6 & 3.9 & 2.9 & Mesial & 12 & & 22 & Mesial & 4.3 & 4.3 & 4.3 & 4.2 \\
\hline 4 & 4 & 3.6 & 2.8 & Distal & & & & Distal & 2.5 & 2.4 & 2.4 & 2.6 \\
\hline
\end{tabular}

To accomplish the goals of the study, Independent samples T-test was conducted to compare the mean bone loss from the implant neck for both types of implants used, at a significance level of $95 \%$ "Table. 2 ".

Table 2. Mean differences in bone loss levels between implants with beveled neck and non-beveled neck.

\begin{tabular}{|c|c|c|c|c|c|c|c|c|c|c|c|}
\hline & \multicolumn{4}{|c|}{ Non-Beveled Implant Neck } & \multicolumn{4}{|c|}{ Beveled Implant Neck } & \multicolumn{3}{|c|}{ T Tesets } \\
\hline & Mean & SD & $\begin{array}{l}\text { Min. } \\
\text { Value }\end{array}$ & $\begin{array}{l}\text { Max. } \\
\text { Value }\end{array}$ & Mean & SD & $\begin{array}{l}\text { Min. } \\
\text { Value }\end{array}$ & $\begin{array}{l}\text { Max. } \\
\text { Value }\end{array}$ & $\mathbf{t}$ & Sig & $\begin{array}{l}\text { Mean } \\
\text { Difference }\end{array}$ \\
\hline $\begin{array}{l}\text { The Day of the } \\
\text { restoration }\end{array}$ & 1.738 & 1.28 & 0.2 & 4.6 & 1.7 & 0.79 & 0.1 & 4.3 & .121 & .905 & .0388 \\
\hline $\begin{array}{l}3 \text { months after } \\
\text { the restoration }\end{array}$ & 2.405 & 1.41 & 0.2 & 4.4 & 1.9417 & 0.93 & 0.7 & 4.3 & 1.281 & .207 & .4638 \\
\hline $\begin{array}{l}6 \text { months after } \\
\text { the restoration }\end{array}$ & 2.8 & 1.49 & 0.4 & 4.5 & 2.037 & 0.86 & 0.8 & 4.3 & 2.083 & .044 & .7625 \\
\hline $\begin{array}{l}18 \text { months after } \\
\text { the restoration }\end{array}$ & 2.9111 & 1.26439 & .70 & 4.50 & 2.1417 & .73421 & 1.10 & 4.20 & 2.481 & .017 & .7694 \\
\hline
\end{tabular}

From the table above we can see that the mean bone loss from the implant neck on the day of the restoration for both systems was close at 1.7389 for implants with a non-beveled neck and 1.7000 for implants with a beveled neck.

Three months after the restoration, mean differences started to appear, with a mean value of 2.4056 for implants with a non-beveled neck and 1.9417 for implants with a beveled neck.

Six months after the restoration, a clear difference in the means emerged with a value of 2.8000 for implants with a non-beveled neck and 2.0375 for implants with a beveled neck. That is lesser bone loss was noticed for implants with a beveled.

Likewise, eighteen months after the restoration, a clear difference in the means emerged, with a value of 2.9111 for implants with a non-beveled neck and 2.1417 for implants with a beveled neck. That is lesser bone loss was noticed for implants with a beveled implant.

Three months after the restoration, we notice that the sig. value is larger than 0.05 . That is, no statistically significant differences existed although the mean differences reached 0.46389 in favor of implants with a beveled neck [lowest]. However the standard deviation was 1.41 for implants with a non -beveled neck due to the absence of statistical significance.

Six months after the restoration, we notice that the sig. value is smaller than 0.05 . That is, no statistically significant differences existed although the mean difference reached 0.7625 in favor of implants with a beveled neck (lowest).

Eighteen months after the restoration, we notice that the sig. value is smaller than 0.05 . That is no statistically significant differences existed although the mean difference reached 0.7694 in favor of implants with a beveled neck (lowest). 
From "Fig. 12", we can notice a convergence in the mean value on the day of restoration. However 3 months later [post restoration], the difference became apparent between the two implant types where the value of the non-beveled neck implants with was significantly higher. Although the implants with a beveled neck maintained an almost comparable level after 3 months, 6 months and 18 months, the differences were large for non-beveled neck implants after 3 months, 6 months and 18 months.

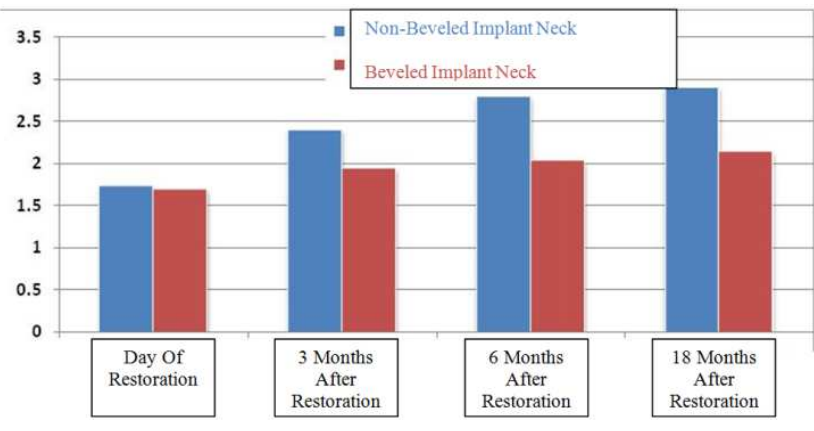

Figure 12. A comparison between the means of the two implant types.

\subsection{The Inter-implant Distance}

The implants were inserted into their sites so that the distance between every two implants was $3 \mathrm{~mm}$. When the panoramic radiographs were taken, the inter-implant dimensions were measured and the results were recorded as follows, "Table. 3".

Table 3. Descriptive statistics of the inter-implant distance.

\begin{tabular}{lc}
\hline SE & $-\mathbf{x}$ Mean \\
\hline $0,35 \mathrm{~mm}$ & $2,8 \mathrm{~mm}$ \\
\hline
\end{tabular}

\subsection{The Distance between the Contact-Point and the Tip of the Bone}

Ceramic-metal restorations were manufactured above the implants so that the distance between the contact point and the tip of the crestal bone was $5 \mathrm{~mm}$ upon restoration. "Table. 4". outlines the mean radiographic dimensions taken on the day of restoration between the contact points between the implant-restoration and the crestal bone tip corresponding to each one, as can be seen in "Fig. 11".

Table 4. Descriptive statistics of the distance from the contact point to the tips of the bone immediately post restoration.

\begin{tabular}{ll}
\hline SE & Mean $^{-} \mathbf{x}$ \\
\hline $0,41 \mathrm{~mm}$ & $5,05 \mathrm{~mm}$ \\
\hline
\end{tabular}

\section{Discussion}

Schwartz-Arad [14] used panoramic radiographs to measure the peri-implant bone loss to compare between the immediate and delayed loading in a similar method to that used in our study.

It was noticed that after the implant-restoration, the bone started to recede coronally vis-à-vis the implant neck. This was confirmed by the majority of studies. For instance, Wagenberg BD [15] evaluated 1178 implants with a time lapse of 22 years and found a permanent bone loss which however did not exceed $1.5 \mathrm{~mm}$ on average during these years.

Hermann [4.9,10] discussed what is known as the saucerization phenomenon, which is the form or shape that results from a lack of connection between the bone and the implant neck, "Fig. 1".

The goal of many of these studies was to preserve the periimplant tissue over the long-term as marginal bone loss in the early stages following the restoration has been noticed. This loss was apparent at the implant-abutment junction (IAJ). Frequently, migration is likely to occur in the apical direction around the implant for the purpose of isolating the bone and protecting it from inflammation/irritation which is caused by several factors:

- Bacterial leakage.

- Micro movements.

- Stress transfer to opposite side of the implant-abutment junction.

The concept of platform switching expresses the adjacent surface positioning to the implant-abutment junction (IAJ), in an area proximal to the horizontal surface to the implant neck. Hence this surface (IAJ) becomes distant from the marginal bone. Thereby, both bacterial leakage, minor movements and stress is kept at bay from the marginal bone. This decrease the likelihood of marginal bone migration in the apical direction. Many studies have pointed out the existence of several commercial implant brands with platform switching $[16,17]$.

In other studies, the platform switching concept was realized by using abutments with a smaller diameter than that of the implant neck, so that the horizontal inter-distance is achieved at the level of the implant-abutment junction [18].

The majority of the comparative studies registered lower bone loss in implants with platform switching [16,17] albeit some scientists have noted the lack of substantial differences [19].

Lazzara [20] supported the concept of platform switching, which lead him to conclude after an observation period of 13 years, the lack therein of bone loss in comparison with the conventional two-piece systems. This finding corroborated the theory of scientist Misch [21] which stated that the concentration of stress is the cause of the resultant crestal bone loss.

Many scientists have emphasized the role of changing the point of contact in the automatic reformation of the gingival papilla [22]. Several studies highlighted the relation between the contact point and the crestal bone level and the absence or presence of a gingival inter dental papilla.

The study by Kang et al. [23] revealed a strong relation between the distance [contact point and crestal bone tip] and filling the distance with gingival papilla. The result showed that when the distance between the contact point and the tip of the bone is $5 \mathrm{~mm}$ or less, the gingival papilla will always fill the space completely at a rate of $100 \%$. In cases where the contact point was higher in the direction of the incisor, 
the soft tissue rarely fills the inter-dental space. The presence of gingival papilla at a distance of $7 \mathrm{~mm}$ between the bone tip and the contact point was very rare, less than $25 \%$.

Since preserving the crestal bone level supporting the periimplant soft tissue is related to preserving these soft tissues $[3,4,5]$, it follows that the appropriate distance of the contact point from the tip of the crestal bone and attaining the best condition for the gingival papilla is solely related to the bone level below the contact point.

In this study, the distance between the contact point and the tip of the crestal bone beneath it was unified at approximately $5 \mathrm{~mm}$ as has been outlined in "table. 4". This was done to unify the research conditions when comparing the two implant systems.

Similarly, in this research, the conditions were unified to realize the concept of platform switching in implants with a beveled neck from the manufacturing company [16,17], and achieved in implants with a non-beveled neck by reducing the diameter of the abutment [18]. This in turn kept issues of marginal leakage, micro movements and stresses at the implant-abutment junction from affecting the comparison between the two systems, beveled neck and non-beveled neck, by unifying the condition of platform switching in both systems.

Most studies have stressed on allowing a distance of $3 \mathrm{~mm}$ between every two adjacent implants as Tarnow et al [22] mentioned in their study conducted on 36 patients who benefited from Titanium implants at the University of New York. The bone loss between adjacent implants increased as the distance between them decreased. This was a result of loss in the horizontal crestal bone complex in this zone. $\mathrm{He}$ confirmed that the distance between the adjacent implants must be around $3 \mathrm{~mm}$ or more.

Scarano et al [24] conducted a study on dogs to examine the relation between peri-implant bone loss and inter-implant distances (after 12 months of placing the implants without loading). The results of their study showed that the amount of peri-implant vertical bone loss was $0.28 \mathrm{~mm}$ for implants that were $1 \mathrm{~mm}$ apart. Thus, peri-implant bone loss is strongly related to the distance between one implant and another "Fig. 12 "'.

In this study, the implants were inserted in their sites so that the inter-implant distance was about $3 \mathrm{~mm}$. After the radiographs were taken, the dimensions measured between the implants were measured as can be seen from "Table. 3". Care was taken to avoid dimensional disparities between the adjacent implants of both systems examined, once again to unify the study conditions.

Vidyasagar et al. [25] discussed several factors that affect the success of the implant such as the type and amount of bone in the implant modeling and implant neck topography as well as the role of designs that lead to bone-thickening in areas with low bone density.

Lindhe et al [26] wrote about changing the topography of the implant surface to yield greater roughness which in turn results in a larger contact surface allowing for more contact between the implant neck and the bone. He suggested as examples, acid etching the implant surface or fitting it with a plasmic coat.

Diago M. et al. [27] provided a medical literature review for the years (1998-2000) on the topics of bone loss at the implant neck surfaces and on the differences between polished neck and machined or rough neck with microthreading and rough neck without micothreading. The results showed that the majority of studies did not find a difference between a polished surface and a rough surface without microthreading with regards to bone loss. As for microthreading, it had superior results when it was available on rough surfaces.

However, in this study all the implants were inserted in the anterior zone of the jaws on the both sides of the straight mid-facial line in a symmetrical manner for systems, beveled neck and non-beveled neck in order to unify the type of bone. The implant neck topography chosen for both systems in this study was of the rough neck type with no microthreading. The implants of both systems were submerged below the bone level to unify the research conditions. The remaining difference between the two systems was whether to bevel the implant neck or not.

The coronal peri-implant bone loss was measured periodically to examine the impact of beveling in the design of the implant neck on the levels of bone supporting the perirestoration tissues. The measurements were taken after complete osseointegration and placement of the final restoration. Another measurement was taken 3 months post restoration, another was taken 6 months post restoration and a final measurement was taken 18 months post restoration, "Table. 1".

Independent samples T-test was carried out to calculate the differences in the coronal peri-implant bone loss depending on the type of implant used as outlined in "Table. 2".

The results of this study did not reveal any statistically significant differences in the level of peri-implant bone loss between the implants with a beveled neck and implants with a non-beveled neck on the day of restoration placement

This finding confirmed the possibility of comparing both systems by periodic observation post restoration, as no differences were recorded on the day of restoration.

This study showed the existence of differences in the level of peri-implant bone loss in the two systems aforementioned as in "Fig. 12". It can be observed that the mean bone loss for implants with a non-beveled neck was greater than the mean bone loss for implants with a beveled neck. However, the standard deviation was relatively large in implants with a non-beveled neck because there were clear differences between the two systems above.

The study showed considerable statistically significant differences in the peri-implant neck bone loss levels 6 months and after 18 months post restoration between implants with a beveled neck and implants with a nonbeveled neck. Greater bone loss was found to have taken place in the implants with a non-beveled neck compared to those occurring in implants with a beveled neck, "Table. 2". The last finding confirmed the superiority of the implants 
with a beveled neck over those with a non-beveled neck in terms of post restorative, peri-implant neck bone loss. Yet, this study does not elevate implants with a beveled neck to the status which its defenders claim.

Despite its comparative superiority, these implants have experienced an actual peri-implant bone loss in the post restoration phases as can be seen in "Fig. 12". This contradicted the claims by the manufacturing company that the beveled does not only preserve the crestal bone but that it also provides a chamber for the bone that forms above the implant neck after the osseointegration phase.

The results of our study corroborated those of other researchers who have confirmed the incidence of initial post restorative bone loss, especially in the first year after the implant surgery regardless of the implant type. The results of the study showed the incidence of an initial bone loss although there were differences in this loss between the two different systems pertaining to the design of the implant neck

Unifying the research conditions generally, and specifically the concept of platform switching, the concept of submerged implants and the concept of rough and polished implant neck surfaces and with the differences in modeling the implant necks, bone loss occurred during this study. This reflected the fact that bone loss is a difficult issue to overcome in different implant systems and is likely to negatively affect the soft tissues that are supported by this bone according to $[3,4,5]$ Consequently, the negative result of the appearance of the soft tissue will diminish the esthetic aspect of the implant-restoration.

As for the difference in the level of bone loss between the two chosen systems in this study, it is likely to motivate us to use the system with lesser bone loss in the anterior esthetic zones of the jaws taking into consideration the existing bone loss.

This research does not cover up the many difficulties that have faced this entire study generally. For instance, the measurement method used depended on parts of the millimeter which could result in some measurement errors. We also recommend the search for more accurate measurements from the radiographs which could be prone to mutations in radiography or standardization, which tend to be common errors in X-ray radiography.

\section{Conclusions and Recommendations}

This study compared two dental implant systems, one with implants that have a beveled neck and another with implants that have a non-beveled neck in order to evaluate the level of bone support around an implant-crown. The results of the study did not show any statistically significant differences in the early stages of the restoration/prosthesis. Yet, after 6 months and up to 18 months post restoration, statistically significant differences emerged verifying that the periimplant bone loss occurring in implants with a beveled neck was less than that occurring around implants with a nonbeveled neck, confirming the incidence of an initial bone loss following the restoration in all cases.
Thus this study declare the the occurrence of peri-implant crestal bone loss, known as the saucerization phenomenon, occurring in implants with a beveled neck was less than that occurring around implants with a non-beveled neck.

We recommend that a similar study be conducted using computerized cross-sectional radiographs to investigate bone formation and loss in the buccal zone of the implants, which is very important from an esthetic aspect. We also recommend the study of design morphology of the tissues surrounding the implant-restoration in both designs. Finally, we recommend the search for new techniques to solve the problem of peri-implant bone loss in the anterior zones of the jaws.

\section{References}

[1] Issa, Nazih. The dental implantation according to osseointegration- clinical evaluation-. Damascus University, Syria. 1994,pp.146.

[2] Jan Lindhe, Niklaus P.Lang, Thorkild Karring. Clinical Periodontology and Implant Dentistry. s.l.: Blackwell Publishing Ltd, 2008, pp. 7.

[3] Bengazi, F., Wennstro"m, J. \& Lekholm, U. Recession of the soft tissue margin at oral implants.A 2-year longitudinal prospective study. Clinical Oral Implants Research. 1996, pp. 303-310.

[4] Hermann JS, Cochran DL, Nummikoski PV, Buser D. Crestal bone changes around titanium implants. A radiographic evaluation of unloaded nonsubmerged and submerged implants in the canine mandible. J Periodontol . 1997, Vol. 68, pp. 1117-1130.

[5] Nishimura RD, Chang TL, Perri GR, Beumer J 3rd. Restoration of partially edentulous patients using customized implant abutments. Pract Periodontics Aesthet Dent. 6, 1999 , Vol. Aug 11, pp. 669-76.

[6] Fürhauser R, Florescu D, Benesch T, Haas R, Mailath G, Watzek G. Evaluation of soft tissue around single-tooth implant crowns: the pink esthetic score. Clin Oral Implants Res. 2005, Vol. 6, 16, pp. 639-44.

[7] Heydenrijk, K., Meijer, H. J., van der Reijden, W. A., Raghoebar, G. M., Vissink, A. \& Stegenga, B. Microbiota around root-form endosseous implants: a review of the literature. The International Journal of Oral \& Maxillofacial Implants. 2002, Vol. 17, p. 829.

[8] Herman, M. R., Dornbusch, S.M., Herron, M.C., \& Herting, J.R. The influence of Family Regulation, Connection, and Psychological Autonomy on Six Measures of Adolescent Functioning. Journal of Adolescent Research. 1997, Vol. 12, pp. 34-67.

[9] Hermann JS, Buser D, Schenk RK, Higginbottom FL, Cochran DL. Biologic width around titanium implants. A physiologically . 2000a.

[10] Hermann JS, Buser D, Schenk RK, Schoolfield JD, Cochran DL. Biologic Width around one- and two-piece titanium implants. Clin Oral Implants Res. 2001a, Vol. 12, pp. 559-571. 
[11] Nickenig, H.J., Wichmann, M., Schlegel, K.A., Nkenke, E.\&Eitner, S. Radiographic evaluation of marginal bone levels adjacent to parallel-screw cylinder machined-neck implants and rough-surfaced microthreaded implants using digitized panoramic radiographs. Clinical Oral Implants Research. 2009, Vol. 20, pp. 550-554.

[12] Bratu, E.A., Tandlich, M. \& Shapira, L. A rough surface implant neck with microthreads reduces the amount of marginal bone loss: a prospective clinical study. Clinical Oral Implants Research. 2009, Vol. 20, pp. 827-832.

[13] www.Bicon.com. [Online]

[14] Schwartz-Arad D, Herzberg R, Dolev E. The prevalence of surgical complications of the sinus graft procedure and their impact on implant survival. J Periodontol. 75, 2004, pp. 511516.

[15] Wagenberg BD, Froum SJ, Eckert SE. Long-term bone stability assessment around 1,187 immediately placed implants with 1- to 22-year follow-up. Int J Oral Maxillofac Implants. 2013, Vol. 2, 28, pp. 605-12.

[16] Canullo L, Fedele GR, Iannello G, Jepsen S. Platform switching and marginal bone-level alterations: the results of a randomizedcontrolled trial. Clin Oral Implants Res. 2010, Vol. 21, pp. 115-21.

[17] Fickl S, Zuhr O, Stein JM, Hürzeler MB. Peri-implant bone level around implants with platform-switched abutments. Int $J$ Oral Maxillofac Implants. 2010, Vol. 25, p. 577.

[18] Veis A, Parissis N, Tsirlis A, Papadeli C, Marinis G, Zogakis A. Evaluation of peri-implant marginal bone loss using modified abutment connections at various crestal level placements. Int $J$ Periodontics Restorative Dent. 2010, Vol. 30, pp. 609-17.

[19] Crespi R, Capparè P, Gherlone E. Radiographic evaluation of marginal bone levels around platform-switched and non- platformswitched implants used in an immediate loading protocol. Int J Oral Maxillofac Implants. 2009, Vol. 24, pp. 920-6.

[20] Lazzara RJ, Porter SS. Platform switching: a new concept in implant dentistry for controlling postrestorative crestal bone levels. Int J Periodontics Restorative Dent. 2006, Vol. 26, pp. 9-17.

[21] Misch, Carl E. CONTEMPORARY IMPLANT DENTISTRY Third Edition. Canada : MOSBY ELSEVIER, 2008, pp. 72.

[22] al., Tarnow DP et. The effect of the distance from the contact point to the crest of bone on the presence or absence of the interproximal dental papilla. J Periodontol. 1992.

[23] Wu, Yu-Jen, Tu1, Yu-Kang and Huang2, Shay-Min. The Influence of the Distance from the Contact Point to the Crest of Bone on the Presence of the Interproximal Dental Papilla. Chang Gung Med. 2003.

[24] Scarano A, Piattelli M, Caputi S, Favero GA, Piattelli A. Bacterial adhesion on commercially pure titanium and zirconium oxide disks: an in vivo human study. $J$ Periodontol. 2004, Vol. 75, pp. 292-296.

[25] Linish Vidyasagar, Peteris Apse. Dental Implant Design and Biological Effects on Bone-Implant Interface. Stomatologija, Baltic Dental and Maxillofacial Journal. 2004, Vol. 6.

[26] Jan Lindhe, Niklaus P.Lang, Thorkild Karring. Clinical Periodontology and Implant Dentistry. s.l.: Blackwell Publishing Ltd, 2008, pp.1048.

[27] Aloy-Prósper A1, Maestre-Ferrín L, Peñarrocha-Oltra D, Peñarrocha-Diago M. Marginal bone loss in relation to the implant neck surface: an update. 2011, Vol. 3, 16. 